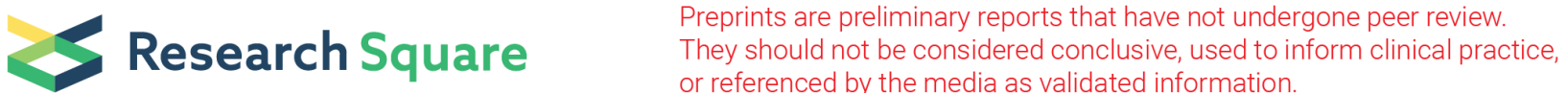 \\ Antidiabetic Properties and Possible Mechanism of the Traditional Chinese Medicine Yi Qi Yang Yin Recipe in $\mathrm{Db} / \mathrm{db}$ Mice
}

Hongmei Lin

Beijing University of Chinese Medicine https://orcid.org/0000-0001-7598-3580

\section{Ziying Xu}

Beijing University of Chinese Medicine

\section{Baosheng Zhao}

Beijing University of Chinese Medicine

\section{Jingxuan Zhang}

Beijing University of Chinese Medicine

\section{Zilan Zhang}

Beijing University of Chinese Medicine

\section{Weiling Wang}

Beijing University of Chinese Medicine

Ting Wang ( $\square$ wangting1973@sina.com )

Beijing University of Chinese Medicine

\section{Research}

Keywords: Yiqi Yangyin, Antidiabetic, db/db mice, Gluconeogenesis, Glycogen synthesis, Multi-targeting

Posted Date: November 23rd, 2021

DOl: https://doi.org/10.21203/rs.3.rs-1029361/v1

License: (a) This work is licensed under a Creative Commons Attribution 4.0 International License. Read Full License 


\section{Abstract \\ Background}

Yi Qi Yang Yin Recipe (YQYY) is a well-known clinical prescription used in Traditional Chinese Medicine (TCM) that ameliorates type 2 diabetes. The aim of the present study was to comprehensively evaluate the efficacy of YQYY granules and explore their mechanism of action.

\section{Methods}

$\mathrm{db} / \mathrm{db}$ mice were studied as an animal model of type 2 diabetes. After administered with YQYY for eight weeks, food and water consumption, levels of fasting blood glucose, glycosylated serum protein, and liver and pancreas tissue morphology were investigated. In addition, RT-PCR and Westernblot analysis were used to determine the expression of genes and proteins related to glycogen synthesis and gluconeogenesis pathways in the liver.

\section{Results}

YQYY resulted in significantly reduced food and water consumption, and lower fasting blood glucose and glycated serum protein levels. Furthermore, the proliferation of a-cells in $\mathrm{db} / \mathrm{db}$ mouse pancreatic tissue decreased and liver tissue morphology was significantly ameliorated. YQYY upregulated the expression of phosphorylated GSK-3 $\beta$ and GS proteins in $\mathrm{db} / \mathrm{db}$ mouse liver tissue, and promoted the synthesis of liver glycogen. Additionally, AMPK was activated, PEPCK and G6Pase gene expression levels decreased, and consequently, gluconeogenesis in the liver was inhibited. Therefore, YQYY improves diabetic phenotyp, suggesting that YQYY could be a prospective agent for preventing and treatment diabetes .

\section{Introduction}

Type 2 diabetes mellitus (T2DM) is a complex and severe metabolic disease caused by peripheral insulin resistance and islet $\beta$-cell dysfunction. It is a prevalent global disease with serious consequences to health. Epidemiological studies suggest that $9.3 \%$ of the global population suffers from diabetes, the proportion likely to rise to $10.2 \%$ by the end of 2030 , of which $90 \%$ will be T2DM ${ }^{1,2}$. The effectiveness of the majority of hypoglycemic synthetic drugs declines during long-term treatment. For example, glycosylated hemoglobin can be reduced to $7 \%$ when metformin is first administrated. However, it is effective in only $42 \%$ of patients after $2-5$ years of use ${ }^{3}$. In recent years, combination drug therapy has been the focus of attention among medical researchers, providing a more efficacious response, for example, thiazolidinedione with metformin, glimepiride with metformin, GLP-1RA with SGLT2i, or GLP-1RA with DPP-4 ${ }^{4-7}$. Although the oral administration of additional Western medicines generally increases the incidence and severity of side effects, TCM has been widely used in clinical treatments (in China, Japan, Korea, and other East Asian countries) for thousands of years ${ }^{8}$. TCM provides a unique approach to therapy through synergistically treating metabolic diseases via a multi-targeting approach using multiple compounds. By virtue of their inherent compatibility, multiple compounds synergistically target the pathophysiological mechanism and not only avoid side effects such as hypoglycemia, the problem of drug resistance is also fundamentally prevented. 
In conventional concepts of TCM, T2DM is regarded as "xiaoke". A deficiency of Yin and Qi, and excessive dryness and heat are the main contributors to the pathogenesis of "xiaoke" ${ }^{9}$. YQYY is a clinical prescription for the treatment of T2DM in patients that have a syndrome in which there is a deficiency of Qi and Yin. It is formed from a decoction of Angelica Liuhuang, as recorded in "The Hoard of Lan Shi" by Li Dong-Yuan. YQYY has been used clinically for many years and consists of seven herbs, including Astragalus mongholicus Bunge,

Rehmannia glutinosa (Gaertn.) DC, Coptis chinensis Franch, Crataegus pinnatifida Bunge, Mori fructus of Morus alba L. etc. It not only reduces blood glucose in T2DM, but also improves clinical manifestations caused by excessive drinking, over eating, fatigue, irritability, etc. Previous studies have shown that Astragalus mongholicus, an important herb with in YQYY, inhibits the apoptosis of $\beta$-cells in islets, the principal pathological mechanism resulting in their functional degeneration in T2DM, through immune regulation ${ }^{10,11}$. Rehmannia glutinosa functions by nourishing Yin and reducing fire, manifested mainly as the regulated release of glucocorticoids (GC), inhibition of the excessive secretion of gastric acid, gluconeogenesis, and lipolysis ${ }^{12,13}$. The main active ingredient in Coptis chinensis, the adjuvant herb in the prescription, is berberine, which decreases inflammatory factors, improves insulin resistance, and inhibites glycogenolysis ${ }^{10,14,15}$. The active ingredients in Crataegus pinnatifida and Mori fructus are organic acids, flavonoids, and polyphenols which significantly reduce serum cholesterol and triglycerides, thereby effectively preventing and treating atherosclerosis ${ }^{16-18}$.

$\mathrm{db} / \mathrm{db}$ mice are widely used in animal models of T2DM. They have a mutation in the leptin receptor (Lepr) gene that prevents a response to the satiety hormone, leptin. By never being sated, anabolism becomes greater than catabolism, causing animals to accumulate fat and become obese, gradually developing severe diabetes with significant hyperglycemia. $\mathrm{db} / \mathrm{db}$ mice exhibit characteristics similar to the clinical symptoms of T2DM in humans, including polydipsia, polyphagia, polyuria, obesity, hyperglycemia, hyperinsulinemia, insulin resistance, and abnormal lipid metabolism ${ }^{9,19}$. These are consistent with the symptoms of T2DM as described in TCM.

In the present study, UHPLC-Orbitrap MS technology was used to identify the principal chemical components within the YQYY prescription. The effects on improving diabetic phenotype of YQYY and the possible mechanisms of these effects were explored in $\mathrm{adb} / \mathrm{db}$ animal model.

\section{Materials And Methods}

\section{Materials and Preparation of YQYY samples}

Metformin tablets were purchased from Sino-American Shanghai Squibb Pharmaceutical Co., Ltd. (catalog number: ABK6039). Accu-Chek blood glucose test strips were obtained from Roche (catalog numbers: 478041, 478240). Glycosylated serum protein detection kits were acquired from Beijing Lideman Biochemical Technology Co., Ltd. (catalog number: GS7322) while the following test kits were obtained from Beckman Coulter Laboratory Systems Co., Ltd. Triglycerides (catalog number: AUZ6343), total cholesterol (catalog number: AUZ7319), lowdensity lipoprotein (catalog number: AUZ6224), and high-density lipoprotein (catalog number: AUZ6552).

YQYY extract was provided by Jiangxi Baoli Pharmaceutical Co., Ltd. (catalog number: 191201). The process for preparing the prescription was as follows: the herbs in the recipe were decocted in a 10 -fold volume of water 3 times, each for $1 \mathrm{~h}$. The boiled liquid was centrifuged while hot $(6000 \mathrm{~g}, 10 \mathrm{~min})$ and then concentrated to a relative density of $1.25-1.30$ at reduced pressure $\left(60^{\circ} \mathrm{C}\right)$. The concentrate was vacuum dried $\left(80^{\circ} \mathrm{C}\right)$, then crushed, and filtered through a no. 5 screen ( 80 mesh). 


\section{Analysis of ingredients using UHPLC-Orbitrap MS}

\section{Chromatographic and mass spectrometric conditions}

Analysis was performed using a Thermo Scientific Vanquish Ultra Performance LC system coupled to a Thermo Scientific Q Exactive Plus mass spectrometer equipped with a heated electrospray ionization (HESI) source (Thermo Scientific, Santa Clara, CA, USA). Separation of the samples was performed through an Aquity UPLC®BEH C18 column $(2.1 \mathrm{~mm} * 100 \mathrm{~mm}, 1.7 \mu \mathrm{m})$. Gradient elution was employed using a $0.1 \%$ aqueous solution of formic acid as solvent $A$ and acetonitrile as solvent $B$. The following gradient was used: $0-5 \mathrm{~min}(5 \%$ B), $5-35 \mathrm{~min}(5-85 \% \mathrm{~B}), 35-35.1 \mathrm{~min}(85-5 \% \mathrm{~B}), 35.1-38 \mathrm{~min}(5 \% \mathrm{~B})$. The flow rate was $0.3 \mathrm{~mL} / \mathrm{min}$, with an injection volume of $2.0 \mu \mathrm{L}$. Negative ion ionization was used as it allows the detection of a greater number of compounds with greater sensitivity than possible with positive mode. The spray and capillary voltages were set to $3.0 \mathrm{kV}$ and $35.0 \mathrm{~V}$, respectively. The tube lens voltage was $110 \mathrm{~V}$ and source temperature was set to $350^{\circ} \mathrm{C}$. Nitrogen (purity $>99.99 \%$ ) was used as both the sheath (40 arb) and auxiliary gas (20 arb). A full-scan range from 100 to $2000 \mathrm{~m} / \mathrm{z}$ was used.

\section{Preparation of test samples}

YQYY samples (2 g, batch number: 191201) were extracted ultrasonically with $25 \mathrm{~mL}$ methanol for $30 \mathrm{~min}$. The supernatant was filtered through a $0.22 \mu \mathrm{m}$ filter.

\section{Animals and treatment}

A total of 75 8-week old male BKS-DB homozygous and 15 wild-type mice that were specific pathogen-free (SPF) grade were purchased from Jiangsu Jizui Pharmacology Co., Ltd. The production license number for the experimental animals was SCXK (Su) 2018-0008. The animals were maintained in an isolated environment in an animal house at Beijing University of Chinese Medicine (temperature: $20 \sim 24^{\circ} \mathrm{C}$, relative humidity: $50-70 \%$, light/dark ratio $12 \mathrm{~h} / 12 \mathrm{~h}$ ). The protocols were approved by the Animal Ethics Committee of Beijing University of Chinese Medicine (No. Bucm-4-2019121101-4090). Following adaptive feeding with general maintenance feed for one week, blood glucose was measured after fasting for $12 \mathrm{~h}$, with values $\geq 11.1 \mathrm{mmol} / \mathrm{L}$ standard for this model. Mice were randomly and equally allocated into 5 groups: Model group $(n=12)$, YQYY high dose group (YQYY-H, $16.43 \mathrm{~g} / \mathrm{kg} / \mathrm{d}, \mathrm{n}=12$ ), YQYY medium-dose group (YQYY-M, $8.21 \mathrm{~g} / \mathrm{kg} / \mathrm{d}, \mathrm{n}=12$ ), YQYY low-dose group (YQYY-L, $4.11 \mathrm{~g} / \mathrm{kg} / \mathrm{d}, \mathrm{n}=12$ ), metformin positive control group (MET, $0.14 \mathrm{~g} / \mathrm{kg}, \mathrm{n}=12$ ), and normal control group (Control, wild-type mice, $n=15$ ). The animals in the model and control groups were administered the equivalent volume of drugs or distilled water by gavage every day for 8 consecutive weeks. The food and water consumption of the mice in each cage was weighed on the same day every week over $24 \mathrm{~h}$, allowing the mean daily food and water consumption of the mice to be calculated.

\section{Fasting blood glucose level}

At the same time every week, animals in each group were fasted but with ad libitum access to drinking water for $12 \mathrm{~h}$. They were weighed and fasting blood glucose (FBG) measured using a glucose meter in blood sampled from their tails (Accu-Chek® Performa, Roche Diagnostics GmbH, Mannheim, Germany).

\section{Serum biochemistry}


Blood samples were collected from the ocular vein of the mice. Serum was obtained by centrifugation of whole blood at $3500 \mathrm{~g}$ for $10 \mathrm{~min}$. The following parameters in the samples were measured using a CX4 Pro automatic biochemical analyzer (Beckman, Brea, CA): glycosylated serum proteins (GSP), triglycerides (TG), total cholesterol (TC), high-density lipoprotein cholesterol (HDL-C), and low-density lipoprotein cholesterol (LDL-C).

\section{Histopathology of pancreases and liver tissue}

At the end of the experiment, necropsies were performed on all animals. The pancreas and liver were fixed in $10 \%$ neutral buffered formalin and embedded in paraffin. Subsequently, the tissue samples were sliced into $3 \mu \mathrm{m}$ thick sections using a rotary microtome, stained with hematoxylin-eosin (H\&E), then observed and examined using an optical microscope at 200× magnification (Carl Zeiss Meditec AG, Germany).

\section{Liver oil red 0 staining and determination of glycogen content}

The liver tissue samples were analyzed by Oil red $O$ staining according to the manufacturer's recommendations. (Solarbio Life Sciences, Beijing, China). The sections were sealed then observed using an Olympus BX41 optical microscope. The glycogen content of the liver tissue was determined in accordance with the instructions of the glycogen kit (Solarbio Life Sciences, Beijing, China).

\section{Immunohistochemistry of pancreas}

Pancreas tissue was fixed in $4 \%$ formalin, embedded in paraffin wax then sectioned for immunohistochemistry. The sections were deparaffinized in xylene then rehydrated through a gradient of alcohol concentrations.

Secondly, the slides were treated with $3 \% \mathrm{H}_{2} \mathrm{O}_{2}$ to block endogenous peroxidase activity, then heated for $2.5 \mathrm{~min}$ in $95^{\circ} \mathrm{C}$ citrate buffer $(10 \mathrm{mmol} / \mathrm{L}, \mathrm{pH} \mathrm{6.0})$ to retrieve the antigens. Thirdly, the slides were incubated with $10 \%$ $\mathrm{BSA}$ at $4^{\circ} \mathrm{C}$ overnight to reduce nonspecific binding. Finally, Power-Vision ${ }^{\mathrm{TM}}$ two-step histostaining reagent and a 3,3-diaminobenzidine tetrahydrochloride substrate kit (ZSGB-Bio, China) were used to visualize antigen localization, in accordance with the manufacturer's instructions.

Slides were stained with anti-glucagon (rabbit monoclonal, diluted 1:5000, ab92517, Abcam) and anti-insulin (mouse monoclonal, diluted 1:2500,66198-1-Ig, Proteintech Group) antibodies, and then incubated with a secondary antibody using a mouse and rabbit-specific HRP/AEC (ABC) detection IHC kit (ab93705, Abcam), following the manufacturer's protocols.

\section{RNA Isolation and Real-Time RT-PCR}

The liver tissue was disrupted in liquid nitrogen, and total RNA was isolated using Trizol reagent (Invitrogen, USA), following the manufacturer's instructions. Equivalent quantities of RNA were reverse transcribed using HiScript II Q Select RT SuperMix for qPCR (+gDNA wiper) (Vazyme, China). Real-time quantitative PCR was

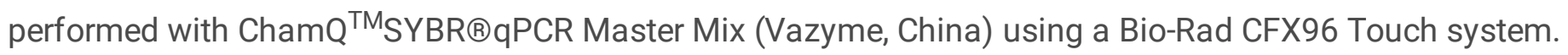
Comparative gene expression analysis was performed using the $\triangle \triangle C T$ method, with GAPDH used as the endogenous control, for normalization. The primers used are as follows:

Table 1Primer sequences for qRT-PCR. 


\begin{tabular}{|lll|}
\hline Genes & & Sequences $\left(5^{\prime}\right.$ to $\left.3^{\prime}\right)$ \\
\hline -actin & Sense & AAATCGTGCGTGACATCAAA \\
\cline { 2 - 3 } & Antisense & AAGGAAGGCTGGAAAAGAGC \\
IRS-1 & Sense & GCTCTCCTTCAGTTCGATGT \\
\cline { 2 - 3 } & Antisense & CTCAACTCCACCACTCTCCT \\
Akt 2 & Sense & GGATGAAGTCGCCCACACAG \\
& Antisense & CCCGATCCTCCGTGAAGACT \\
PEPCK & Sense & CGCGCCTTTGCCTTTCAATC \\
\cline { 2 - 3 } & Antisense & ATGCGGTACAGGCCAGAGAT \\
G6Pase & Sense & CTGTTTGGACAACGCCCGTAT \\
\cline { 2 - 3 } & Antisense & AGGTGACAGGGAACTGCTTTA \\
\cline { 2 - 3 } & & \\
\hline
\end{tabular}

IRS-1: Insulin receptor substrate-1, Akt 2:serine/threonine kinase 2, PEPCK: phosphoenolpyruvate carboxykinase, G6Pase: glucose-6-phosphatase catalytic subunit

\section{Western blot analysis}

Total protein was prepared from tissues using ice-cold RIPA buffer and quantified using a bicinchoninic acid (BCA) protein quantification kit (Dingguo, China). Equal quantities of protein were separated using SDS-PAGE then transferred to polyvinylidene fluoride membranes. Each membrane was incubated with a primary antibody overnight at $4^{\circ} \mathrm{C}$, then with an anti-rabbit or anti-mouse IgG-HRP secondary antibody at room temperature for $2 \mathrm{~h}$. The membrane was then developed using an ECL Kit (Xinsaimei, China).

Table2 Details of antibodies

\begin{tabular}{|llll|}
\hline Protein & Source & Dilution & Cat\# \\
\hline$\beta$-actin & Proteintech & $1: 5000$ & 20536-1-AP \\
\hline AMPK & Cell Signaling & $1: 4000$ & $5832 S$ \\
\hline P-AMPK & Cell Signaling & $1: 200$ & $2535 T$ \\
\hline P-GSK-3 & Cell Signaling & $1: 2000$ & 9323S \\
GS & Cell Signaling & $1: 2000$ & $3886 S$ \\
\hline
\end{tabular}

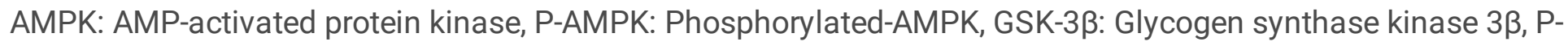

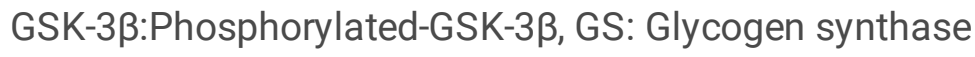

\section{Statistical analyses}

The results are presented as means \pm SD. Data in multiple groups were analyzed using a one-way analysis of variance (ANOVA) using SPSS (version 16.0) software. Differences among means were analyzed using a 
Dunnett T3 multiple comparisons test or by post hoc analysis. $P<0.05$ was considered a significant difference.

\section{Results}

\section{UHPLC-Orbitrap MS analysis of the components in YQYY}

Peaks relating to the principal ingredients of YQYY are displayed in Figure 1. A total of 41 compounds were identified after comparison with standards (Table 3), MS fragmentation behavior, or through exploration of the literature ${ }^{20-24}$. The components identified were mostly triterpene glycosides, alkaloids, flavonoids, oligosaccharides, which have been reported to have a therapeutic effect on T2DM.

\section{YQYY improves the diabetic phenotype in $\mathrm{db} / \mathrm{db}$ mice}

As shown in Figure 2A, the majority of mice in each administration group displayed a trend of decreased food intake compared with the model group. After 4 and 5 weeks of administration, consumption in the YQYY-L group was significantly different from that of the model group $(p<0.05)$. As displayed in Figure $2 \mathrm{~B}$, the daily water consumption of the $\mathrm{db} / \mathrm{db}$ mice in the model group displayed an increasing trend as the experiment proceeded. Compared with the model group, daily water consumption of mice in the low dose and MET groups demonstrated the greatest decrease compared with the model group, reductions that were statistically different after 1,2 , and 6 weeks of administration $(p<0.05)$. As displayed in Figure $2 \mathrm{C}$, the weight of mice in the MET and model groups increased slowly as the experiment proceeded. The bodyweight of the $\mathrm{db} / \mathrm{db}$ mice in each YQYY dosage group increased over the first 3 weeks of administration but stabilized after 4-8 weeks. As shown in Figure 2D, at different time points after the start of drug administration, the FBG levels of $\mathrm{db} / \mathrm{db}$ mice in each group fluctuated, displaying a zigzag pattern, although the FBG level in the MET and YQYY-L groups displayed a decreasing trend compared with the model group. After 6,7 , and 8 weeks of administration, FBG levels in the $\mathrm{db} / \mathrm{db}$ mice in the MET group were significantly lower than in the model group $(p<0.05)$. After 1,6 , and 8 weeks, the FBG levels in the YQYY-L group were significantly lower than those in the model group $(p<0.05)$.

Table 3 Principal ingredients of YQYY as detected by U-HPLC-Orbitrap MS 


\begin{tabular}{|c|c|c|c|c|c|c|c|c|}
\hline $\mathrm{N}$ & $\mathrm{Rt}$ & PPM & $\begin{array}{l}{[\mathrm{M}-\mathrm{H}]-} \\
{[\mathrm{M}+\mathrm{FA}-\mathrm{H}]}\end{array}$ & {$[\mathrm{M}]+$} & $\mathrm{MS}^{2}$ & $\mathrm{MS}^{3}$ & Formula & Identification \\
\hline 1 & 0.86 & & 665.2138 & & 485.2177 & & & Unknown \\
\hline 2 & 0.89 & & 503.1254 & & 341.1084 & 178.9993 & $\mathrm{C}_{18} \mathrm{H}_{32} \mathrm{O}_{16}$ & Trisaccharide \\
\hline 3 & 0.89 & & 341.1089 & & 179.0261 & & $\mathrm{C}_{12} \mathrm{H}_{22} \mathrm{O}_{11}$ & Disaccharide \\
\hline 4 & 0.91 & & 132.9759 & & 114.8762 & 70.8363 & $\mathrm{C}_{4} \mathrm{H}_{6} \mathrm{O}_{5}$ & Malic Acid \\
\hline 5 & 1.23 & & 407.1201 & & 361.1140 & 198.9630 & $\mathrm{C}_{15} \mathrm{H}_{22} \mathrm{O}_{10}$ & Catalpol \\
\hline 6 & 1.25 & & 191.0195 & & 172.9310 & 110.9085 & $\mathrm{C}_{6} \mathrm{H}_{8} \mathrm{O}_{7}$ & Citric Acid \\
\hline 7 & 1.25 & & 353.0719 & & 172.9589 & 110.8929 & $\mathrm{C}_{16} \mathrm{H}_{18} \mathrm{O}_{9}$ & $\begin{array}{l}\text { Chlorogenic } \\
\text { Acid }\end{array}$ \\
\hline 8 & 8.13 & & 443.0961 & & 397.1461 & 281.2482 & $\mathrm{C}_{15} \mathrm{H}_{23} \mathrm{ClO}_{10}$ & Gultinoside \\
\hline 9 & 8.92 & & 193.0506 & & 149.0043 & 133.8924 & $\mathrm{C}_{10} \mathrm{H}_{10} \mathrm{O}_{4}$ & Ferulic Acid \\
\hline 10 & 10.68 & & 401.1453 & & 269.0394 & 160.9684 & $\mathrm{C}_{18} \mathrm{H}_{26} \mathrm{O}_{10}$ & $\begin{array}{l}\text { Benzyl2-O-B-D- } \\
\text { O-pyranosyl--D- } \\
\text { glucopyranoside }\end{array}$ \\
\hline 11 & 10.97 & & & 342.1697 & 297.1341 & 265.0603 & $\mathrm{C}_{20} \mathrm{H}_{24} \mathrm{NO}_{4}$ & Magnoflorine \\
\hline 12 & 11.11 & & 367.1032 & & 191.0132 & 172.9933 & & Unknown \\
\hline 13 & 11.30 & & 785.2509 & & 623.3746 & & $\mathrm{C}_{35} \mathrm{H}_{46} \mathrm{O}_{20}$ & $\begin{array}{l}\text { Digitalis } \\
\text { C/Echinacoside }\end{array}$ \\
\hline 14 & 12.08 & & 799.2660 & & 623.2467 & & $\mathrm{C}_{36} \mathrm{H}_{48} \mathrm{O}_{20}$ & Unknown \\
\hline 15 & 12.38 & & 491.1199 & & 283.0531 & 268.0135 & $\mathrm{C}_{22} \mathrm{H}_{22} \mathrm{O}_{10}$ & $\begin{array}{l}\text { Calycosin-7- } \\
\text { Glucoside }\end{array}$ \\
\hline 16 & 12.66 & & 463.0886 & & 301.1351 & & $\mathrm{C}_{21} \mathrm{H}_{20} \mathrm{O}_{12}$ & Isoquercetin \\
\hline 17 & 12.96 & & 623.1981 & & 461.2190 & 315.2405 & $\mathrm{C}_{29} \mathrm{H}_{36} \mathrm{O}_{15}$ & Acteoside \\
\hline 18 & 13.37 & & & 322.1071 & 307.0952 & 279.1095 & $\mathrm{C}_{19} \mathrm{H}_{16} \mathrm{NO}_{4}$ & Berberrubine \\
\hline 19 & 13.45 & & 623.1981 & & 461.2830 & & $\mathrm{C}_{29} \mathrm{H}_{36} \mathrm{O}_{15}$ & Isoacteoside \\
\hline 20 & 14.63 & & & 338.1380[ & 323.1684 & 294.0664 & $\mathrm{C}_{20} \mathrm{H}_{20} \mathrm{NO}_{4}$ & Columbamine \\
\hline 21 & 14.72 & & & 136.1226 & 321.0932 & 292.1380 & $\mathrm{C}_{20} \mathrm{H}_{18} \mathrm{NO}_{4}$ & Epiberberine \\
\hline 22 & 14.77 & & & 320.0909 & 292.0463 & 277.0022 & $\mathrm{C}_{19} \mathrm{H}_{14} \mathrm{NO}_{4}$ & Coptisine \\
\hline 23 & 14.89 & & & 338.1380 & 323.1148 & 294.0713 & $\mathrm{C}_{20} \mathrm{H}_{20} \mathrm{NO}_{4}$ & Jatrorrhizine \\
\hline
\end{tabular}




\begin{tabular}{|c|c|c|c|c|c|c|c|}
\hline 24 & 15.17 & 475.1248 & & & 267.0130 & $\mathrm{C}_{23} \mathrm{H}_{24} \mathrm{O}_{11}$ & $\begin{array}{l}\text { Odoratin-7-0- } \\
\text { beta-D- } \\
\text { glucopyranoside }\end{array}$ \\
\hline 25 & 15.27 & 475.1248 & & 429.3227 & 267.0130 & $\mathrm{C}_{22} \mathrm{H}_{22} \mathrm{O}_{9}$ & Ononin \\
\hline 26 & 15.44 & 651.2292 & & 475.2136 & & $\mathrm{C}_{31} \mathrm{H}_{40} \mathrm{O}_{15}$ & Isomartynoside \\
\hline 27 & 16.02 & 651.2290 & & 475.2136 & & $\mathrm{C}_{31} \mathrm{H}_{40} \mathrm{O}_{15}$ & Martynoside \\
\hline 28 & 16.05 & & 352.1534 & 337.1692 & 308.1166 & $\mathrm{C}_{21} \mathrm{H}_{22} \mathrm{NO}_{4}$ & Palmatine \\
\hline 29 & 16.09 & 283.0611 & & 268.0159 & 240.0676 & $\mathrm{C}_{16} \mathrm{H}_{12} \mathrm{O}_{5}$ & Calycosin \\
\hline 30 & 16.17 & & 336.1224 & 321.1621 & 292.1002 & $\mathrm{C}_{20} \mathrm{H}_{18} \mathrm{NO}_{4}$ & Berberine \\
\hline 31 & 16.36 & 463.1610 & & 301.1568 & & $\mathrm{C}_{23} \mathrm{H}_{28} \mathrm{O}_{10}$ & $\begin{array}{l}\text { Astraisoflavan- } \\
\text { 7-0- } \beta-D- \\
\text { glucoside } \\
\text { Astraisoflavanin }\end{array}$ \\
\hline 32 & 17.86 & 582.2715 & & 496.3258 & 353.3385 & & Unknown \\
\hline 33 & 19.38 & 267.0662 & & 252.0015 & & $\mathrm{C}_{16} \mathrm{H}_{12} \mathrm{O}_{4}$ & Formononetin \\
\hline 34 & 19.66 & 498.2895 & & 480.3839 & 414.3320 & & Unknown \\
\hline 35 & 19.80 & 829.4592 & & 783.5947 & & $\mathrm{C}_{41} \mathrm{H}_{68} \mathrm{O}_{14}$ & Astragaloside IV \\
\hline 36 & 19.98 & 829.4595 & & 783.5404 & & $\mathrm{C}_{41} \mathrm{H}_{68} \mathrm{O}_{14}$ & Astragaloside III \\
\hline 37 & 20.94 & 871.4699 & & 825.4025 & 765.4916 & $\mathrm{C}_{43} \mathrm{H}_{70} \mathrm{O}_{15}$ & Astragaloside II \\
\hline 38 & 21.67 & 871.4702 & & 825.2760 & 802.7773 & $\mathrm{C}_{43} \mathrm{H}_{70} \mathrm{O}_{15}$ & Isoastragaloside \\
\hline 39 & 21.77 & 407.2801 & & 343.2890 & 289.3150 & & Unknown \\
\hline 40 & 23.14 & 913.4806 & & 867.3031 & 825.7085 & $\mathrm{C}_{45} \mathrm{H}_{72} \mathrm{O}_{16}$ & $\begin{array}{l}\text { Isoastragaloside } \\
\text { I }\end{array}$ \\
\hline 41 & 23.93 & 913.4810 & & 867.3842 & 849.1689 & $\mathrm{C}_{45} \mathrm{H}_{72} \mathrm{O}_{16}$ & Astragaloside I \\
\hline
\end{tabular}

\section{Effect of YQYY on serum biochemical indices in $\mathrm{db} / \mathrm{db}$ mice}

As is typical for the $\mathrm{db} / \mathrm{db}$ animal model of diabetes, the degree of GSP in $\mathrm{db} / \mathrm{db}$ mice increased significantly compared with mice in the control group ( $p<0.01)$ (Table 4). Compared with the model group, the YQYY-L group displayed a significantly lower level of GSP $(p<0.01)$, an effect that was greater than that of metformin $(100.82$ $\mathrm{mmol} / \mathrm{L}$ ). In addition, compared with control mice, serum TC, TG, and HDL-C of mice in the model group were significantly higher $(p<0.05)$. However, compared with the model group, metformin and YQYY failed to significantly reduce serum total cholesterol, triglyceride, and low-density lipoprotein or failed to significantly increase high-density lipoprotein levels. 
Table 4 Effect of YQYY on serum lipids and glycated serum proteins in $\mathrm{db} / \mathrm{db}$ mice

\begin{tabular}{|c|c|c|c|c|c|}
\hline Group & $\begin{array}{l}\text { TC } \\
(\mathrm{mmol} / \mathrm{L})\end{array}$ & $\begin{array}{l}\text { TG } \\
(\mathrm{mmol} / \mathrm{L})\end{array}$ & $\begin{array}{l}\text { HDL-C } \\
(\mathrm{mmol} / \mathrm{L})\end{array}$ & $\begin{array}{l}\text { LDL-C } \\
(\mathrm{mmol} / \mathrm{L})\end{array}$ & $\begin{array}{l}\text { GSP } \\
\text { 『mmol/L】 }\end{array}$ \\
\hline Con $(n=12)$ & $2.30 \pm 0.36$ & $1.30 \pm 0.21$ & $1.66 \pm 0.28$ & $0.34 \pm 0.06$ & $42.89 \pm 13.85$ \\
\hline $\operatorname{Mod}(n=12)$ & $3.60 \pm 0.65^{\# \#}$ & $2.17 \pm 0.61^{\#}$ & $2.54 \pm 0.54^{\# \#}$ & $0.56 \pm 0.46$ & $133.72 \pm 37.88^{\# \#}$ \\
\hline YQYY-H (n=12) & $3.19 \pm 0.73$ & $2.17 \pm 0.52$ & $2.17 \pm 0.52$ & $0.37 \pm 0.13$ & $148.82 \pm 34.98$ \\
\hline YQYY-M $(n=11)$ & $3.09 \pm 0.49$ & $2.20 \pm 0.66$ & $2.18 \pm 0.68$ & $0.53 \pm 0.39$ & $136.67 \pm 29.56$ \\
\hline YQYY-L $(n=12)$ & $3.61 \pm 1.30$ & $3.12 \pm 1.66$ & $2.08 \pm 0.82$ & $0.73 \pm 0.78$ & $88.85 \pm 39.44^{\star \star}$ \\
\hline Met $(n=10)$ & $3.70 \pm 1.51$ & $2.51 \pm 0.76$ & $2.46 \pm 0.65$ & $0.48 \pm 0.24$ & $100.82 \pm 47.12^{*}$ \\
\hline
\end{tabular}

Compared with the control group, \# $p<0.05, \# \# p<0.01$, Compared with the model group, * $p<0.05, * \star p<0.01$.

\section{Liver histopathological observation and hepatic glycogen measurement}

The results indicated that the liver tissue in the control and all $\mathrm{db} / \mathrm{db}$ mice displayed varying degrees of hepatocyte steatosis and/or hepatocyte cytoplasmic vacuity (Figure 3A). Compared with the control group, the degree of liver tissue steatosis in the model group was significantly greater. Compared with the model group, no significant improvement in liver steatosis was observed in the MET group, although in each YQYY dosage group, a decreasing trend of liver steatosis was found, with the YQYY-H and YQYY-M groups having the most apparent difference.

To further establish the effect of YQYY on the hepatocyte steatosis of $\mathrm{db} / \mathrm{db}$ mice, frozen liver tissue sections were stained with Oil red $\mathrm{O}$ stain. The staining of fat in the liver tissues of the control group was slight, essentially consistent with normal tissue morphology. In the model group, more and larger orange lipid droplets were observed in the liver cells due to excessive fat accumulation. In contrast, there were relatively fewer orangered lipid droplets in the hepatocytes in each treatment group (Figure 3B, C), indicating that YQYY-H and YQYY-M significantly reduced the degree of fat accumulation in the liver $(p<0.05)$, in accordance with the result of H\&E.

Liver glycogen content was measured in each group since glycogen synthesis in the livers of $\mathrm{db} / \mathrm{db}$ mice affects FBG levels, and cytoplasmic vacuolation of hepatocytes is induced by glycogen synthesis. As displayed in Figure $3 \mathrm{D}$, compared with control mice, glycogen in the model group was significantly higher under the influence of high glucose $(p<0.01)$. Compared with the model group, metformin and all YQYY dose groups displayed increased liver glycogen content, the YQYY-H and YQYY-M groups exhibited a 1.51 and 1.54-fold greater quantity of glycogen than the model group, differences that were statistically significant $(p<0.01)$.

\section{YQYY prevents morphological changes in pancreatic islets in $\mathrm{db} / \mathrm{db}$ mice}

As shown in Figure 4A, histopathological examination of pancreas tissue demonstrated that islets in the control group displayed clear structural morphology and boundaries, mostly round or oval in shape. The islets in the model group were irregular, with scattered structures and broad distribution of new islet cells. In addition, 
apparent parenchymal cell proliferation was observed in the islets. Compared with the model group, lesions were less apparently resolved in the MET group and each YQYY dose group.

To further investigate the proliferation of islet parenchymal cells, islet $a$ and $\beta$ cells were stained in sectioned pancreatic tissue. In the control group, $\beta$ cells were widely distributed in the inner islet and arranged densely in clusters, while a cells were distributed within the outer islet, mostly in monolayers (Figures 4B, C). In the model group, proliferating $\beta$ cells were also observed, mainly scattered within pancreatic exocrine tissues. The pancreatic islet structures in the model group had significantly higher numbers of a cells, which were scattered in the interior of the islets. Additionally, the relative insulin and glucagon concentrations in the pancreatic islets increased significantly in the $\mathrm{db} / \mathrm{db}$ mice compared with the control group. However, the administration of YQYY and metformin significantly ameliorated the relative intensity levels of insulin and glucagon in the pancreatic islets of the $\mathrm{db} / \mathrm{db}$ mice (Figures $4 \mathrm{D}, \mathrm{E}$ ).

\section{YQYY ameliorates hyperglycemia in $\mathrm{db} / \mathrm{db}$ mice via regulation of the expression of genes or proteins associated with glucose homeostasis}

Following observations that glycogen content in the livers of $\mathrm{db} / \mathrm{db}$ mice were raised by YQYY, the molecular mechanism of the antidiabetic effect due to YQYY was investigated by measuring glycogen synthesis and the expression of proteins and genes related to the gluconeogenesis pathway. As presented in Figure 5, compared with the model group, the expression of G6Pase and PEPCK was significantly lower in the YQYY-L group ( $p<$ 0.01 ) and the MET group ( $p<0.05)$. The expression of IRS-1 and Akt2 in db/db mice were significantly lower than in the control group ( $p<0.01$ ), while the lower expression of IRS-1 and Akt2 were elevated by the treatment of YQYY and MET. As displayed in Figure 6A, the ratio of p-AMPK/AMPK in the model group was significantly lower than in the control group ( $p<0.01)$. Compared with the model group, $\mathrm{p}$-AMPK/AMPK ratio was higher in all the treatment groups, differences that were significant in the YQYY-M and YQYY-L groups $(p<0.01)$. In addition, $\mathrm{p}$ GSK-3 $\beta$ and GS levels in the livers of YQYY groups and MET group were significantly higher than model group(Figures 6B, C).

\section{Discussion}

The etiology and pathogenesis of T2DM are complex and interrelated, resulting in the effectiveness of Western drugs declining after long-term use as they achieve a hypoglycemic effect by targeting a single pathology. In the early stages of the study, the pharmacological function of each herb in YQYY was analyzed. Using the compatibility rules of TCM, we speculated that YQYY may target multiple pathways for the synergistic treatment of T2DM, including the degradation of islet $\beta$ cells $^{11}$, decreased glucose uptake in muscle tissue ${ }^{25,26}$, and increased liver glucose output ${ }^{15,27}$.

The results of the study demonstrated that each dose of YQYY resulted in reduced food and water consumption in $\mathrm{db} / \mathrm{db}$ mice. YQYY-L displayed the most significant reduction in food and water consumption, and significantly reduced FBG and GSP. Due to the lack of dietary control caused by gene deficiency in the $\mathrm{db} / \mathrm{db}$ mice, we hypothesized that increased satiety, and thus reduced food and water consumption, could be a mechanism by which blood glucose was reduced in the YQYY-L group.

Obesity caused by over-consumption in $\mathrm{db} / \mathrm{db}$ mice is accompanied by disrupted lipid metabolism, elevated levels of free fatty acids (FFAs), TG, and LDL-c. Excess FFAs and TG in plasma result in ectopic lipid 
accumulation, such as in the liver, pancreas, or kidneys ${ }^{28}$. In the present study, although YQYY had no apparent effect on resolving serum lipoprotein levels, histopathological observation of H\&E and Oil red O-stained sections indicates that each dose of YQYY ameliorated steatosis and the degree of fat accumulation in liver tissue. The specific reasons require further exploration of the expression of lipid metabolism-related genes and proteins.

Insulin resistance induces a compensatory secretion of insulin by islet $\beta$ cells to maintain normoglycaemia, resulting in their proliferation and hypertrophy of islets ${ }^{29}$. This pathological process was also confirmed in the present study. Insulin storage in the pancreatic islets of $\mathrm{db} / \mathrm{db}$ mice increased significantly, in addition to the islet hypertrophy and the proliferation of islet $\beta$ cells, compared with the control group. However, morphological changes to the pancreatic islets and islet $\beta$ cell proliferation were prevented by the administration of YQYY, suggesting that YQYY could ameliorate islet $\beta$ cell function and improve insulin sensitivity. Additionally, the a cells of proliferating islets tend to secrete an excess of glucagon, leading to increased blood glucose. In the present study, YQYY also significantly inhibited the proliferation of islet a cells in $\mathrm{db} / \mathrm{db}$ mice.

The results of UHPLC-Orbitrap MS analysis indicated that the principal components of YQYY were triterpenoid glycosides, alkaloids, flavonoids, iridoids, phenylpropanol glucoside, the representative active components of each category being astragaloside ${ }^{30}$, berberine ${ }^{26}$, calycosin-7-glucoside $^{31}$, catalpol $^{13,32}$, and acteoside ${ }^{33}$, respectively. Based on previously published studies and the theory of TCM, we speculated that these components were the main active components that improve the function of islet $\beta$ cells, ameliorate the steatosis of liver tissue, prevent gluconeogenesis and increase glycogen synthesis,increase satiety, and inhibit the proliferation of islet a cells in $\mathrm{db} / \mathrm{db}$ mice.

The liver plays a key role in the maintenance of blood glucose homeostasis and the development of diabetes. As blood glucose rises, the liver converts glucose into glycogen ${ }^{34}$. As blood glucose levels decline, glucose is produced by glycogenolysis and gluconeogenesis to maintain blood glucose homeostasis. Promotion of glycogen synthesis and inhibition of gluconeogenesis is an effective method of ameliorating T2DM. The IRS/PI3K/AKT/GS pathway is key to glycogen synthesis ${ }^{35}$. GS is a rate-limiting enzyme for glycogen, whose activity is inhibited by GSK-3 $\beta^{36}$. Activation of PI3K activates Akt, a key kinase in the insulin signaling pathway.

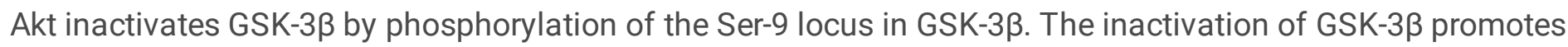
the dephosphorylation of GS, thereby enhancing GS activity and increasing glycogen synthesis ${ }^{37}$. The results of the present study demonstrate that the expression of IRS-1 and Akt genes in the liver tissues of $\mathrm{db} / \mathrm{db}$ mice increased in each treatment group, the increase greatest in the YQYY-M and YQYY-H groups. Furthermore, Western blot analysis also demonstrated that YQYY increased the expression of p-GSK-3 $\beta$ and GS in the liver tissue of $\mathrm{db} / \mathrm{db}$ mice, resulting in increased glycogen content in their livers. These results indicate that YQYY ameliorates the level of FBG and GSP by the promotion of glycogen synthesis via activation of IRS/PI3K/AKT signaling pathway transduction.

PEPCK and G6Pase are rate-limiting enzymes in gluconeogenesis, and the conversion of oxaloacetic acid into phosphoenolpyruvate by PEPCK, the first key step in gluconeogenesis. G6Pase converts glucose 6-phosphate into glucose and is the final stage of gluconeogenesis ${ }^{38}$. In addition, AMPK activation reduces the expression of gluconeogenic enzymes in the liver, including PEPCK and G6Pase. In the present study, YQYY-L significantly reduced gene expression levels of PEPCK and G6Pase in the liver tissue of $\mathrm{db} / \mathrm{db}$ mice, resulting in decreased glucose production in the liver. Moreover, it has been shown that AMPK activation inhibits the dephosphorylation 
of $p-G S K-3 \beta$, which in turn promotes glycogen synthesis ${ }^{37,39}$. These observations are consistent with the results here, with the levels of $\mathrm{p}-\mathrm{AMPK}$, the activated form of AMPK, higher following the administration of YQYY in $\mathrm{db} / \mathrm{db}$ mice, resulting in the activation of GS. The results demonstrate that YQYY can reduce FBG levels in $\mathrm{db} / \mathrm{db}$ mice by promoting the synthesis of liver glycogen and inhibiting gluconeogenesis.

In addition, there is a phenomenon worthy of discussion that is TCM formulas usually have the characteristics of the non-linear dose-effect relationship. In our study, low-dose of YQYY had the best ameliorative effect on food intake, water consumption, FBG, GSP, and the mRNA levels of G6Pase and PEPCK of db/db mice. Medium and high doses of YQYY had the better effect on improving the liver steatosis, increasing glycogen content of livers and the expression of proteins and genes related to the glycogen synthesis. We speculated that it was caused by the synergistic therapeutic effects of TCM via a multi-targeting approach using multiple compounds. The content of catalpol and berberine in low-dose of YQYY was the effective dose in inhibiting gluconeogenesis, while the content of the ingredients such as astragaloside in medium and high doses of YQYY had the effect on improving glycogen synthesis.

\section{Conclusions}

In summary, the results suggest that YQYY granules greatly attenuate the diabetic phenotype in $\mathrm{db} / \mathrm{db}$ mice including excessive drinking and over eating. In addition, we established the effects of YQYY on antidiabetic and the possible mechanisms involved. The administration of YQYY reduced the levels of FBG and GSP by activating transduction of the IRS/PI3K/AKT signaling pathway and AMPK, and via inhibition of PEPCK and G6Pase gene expression. Therefore, we anticipate that YQYY could be utilized for the prevention of diabetes and its treatment. However, the research on the mechanism of YQYY was not comprehensive and in-depth. the test of genome-wide DNA methylation will be conducted in the next for further reveal the mechanism of YQYY on T2DM by analyzing the level of methylation about diabetes-related genes to confirm the multi-targeting action of YQYY in achieving the antidiabetic effect.

\section{Abbreviations}

YQYY: Yi Qi Yang Yin, TCM: Traditional Chinese Medicine, T2DM: Type 2 diabetes mellitus, MET: metformin, FBG: Fasting blood glucose, GSP: glycosylated serum proteins, TG: triglycerides, TC: Total cholesterol, HDL-C: highdensity lipoprotein cholesterol, LDL-C: low-density lipoprotein cholesterol, IRS-1: Insulin receptor substrate-1, Akt

2: serine/threonine kinase 2, PEPCK: phosphoenolpyruvate carboxykinase, G6Pase: glucose-6-phosphatase catalytic subunit, BCA: bicinchoninic acid, AMPK: AMP-activated protein kinase, P-AMPK: Phosphorylated-AMPK,

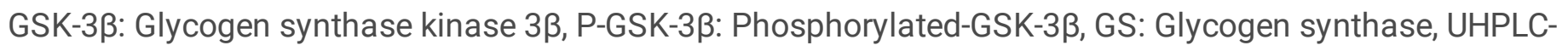
Orbitrap MS: Ultra-high Performance liquid chromatography Q Exactive Plus mass spectrometer

\section{Declarations}

\section{Ethics approval and consent to participate}

All animal experiments were approved by the Animal Ethics Committee of Beijing University of Chinese Medicine (No. Bucm-4-2019121101-4090). 
All authors have approved the manuscript and agree with its submission.

\section{Competing interest}

The authors declare that there are no conflicts of interest.

\section{Funding}

This work was financially supported by the National Natural Science Foundation of

China (grant numbers No.2017ZX 09301011) and Young Teacher Foundation of Beijing University of Chinese Medicine (grant number No. 2019-JYB-JS-023).

\section{Author contributions}

H.M.L., Z.Y.X., and B.S.Z performed the experiments. H.M.L., Z.Y.X., Z.L.Z., and W.L.W analyzed the data and prepared the manuscript. J.X.Z., B.S.Z., and T.W. conceived and led the project. T.W. supported and supervised the research. All authors made contributions to the technical discussions and writing of the manuscript.

\section{Acknowledgments}

We would like to thank Mogoedit (http://en.mogoedit.com/) for English language editing.

\section{Availability of data and materials}

The datasets used in the current study are available from the corresponding author on reasonable request.

\section{Author details}

${ }^{1}$ Beijing Research Institute of Chinese Medicine, Beijing University of Chinese Medicine, Beijing 100029, China.

${ }^{2}$ National Medical Products Administration Key Laboratory for Research Evaluation of Traditional Chinese Medicine, Beijing University of Chinese Medicine, Beijing 100029, China.

\section{References}

1. Saeedi, P. et al. Global and regional diabetes prevalence estimates for 2019 and projections for 2030 and 2045: Results from the International Diabetes Federation Diabetes Atlas, 9(th) edition. Diabetes Res Clin Pract 157, 107843 (2019).

2. Meng, Q. et al. Flavonoids extracted from mulberry (Morus alba L.) leaf improve skeletal muscle mitochondrial function by activating AMPK in type 2 diabetes. J Ethnopharmacol 248, 112326 (2020).

3. Wang, C.Y., Neil, D.L. \& Home, P. 2020 vision - An overview of prospects for diabetes management and prevention in the next decade. Diabetes Res Clin Pract 143, 101-112 (2018).

4. Pilla, S.J., Dotimas, J.R., Maruthur, N.M., Clark, J.M. \& Yeh, H.C. Changes in metformin use and other antihyperglycemic therapies after insulin initiation in patients with type 2 diabetes. Diabetes Res Clin $\operatorname{Pr} 139$, 221-229 (2018). 
5. Kim, J.D. et al. Comparison of Adherence to Glimepiride/Metformin Sustained Release Once-daily Versus Glimepiride/Metformin Immediate Release BID Fixed-combination Therapy Using the Medication Event Monitoring System in Patients With Type 2 Diabetes. Clin Ther 40, 752-761 (2018).

6. J.C. Gómez, J.C.A.L., R.G. Huelgas, D.G. de Lucas, L.M. Polo, J.M.V. Aguilar, J.M.S. Ripoll, J. Ena Combination Therapy with GLP-1 Receptor Agonists and SGLT-2 Inhibitors in Older Patients with Type 2 Diabetes: a RealWorld Evidence Study. Canadian Journal of Diabetes 43 (2018).

7. Tuch, B.E. Clinical use of GLP-1 agonists and DPP4 inhibitors. Pancreatology 16, 8-9 (2016).

8. Peng, Y., Ren, D., Song, Y., Hu, Y. \& Cong, H. Effects of a combined fucoidan and traditional Chinese medicine formula on hyperglycaemia and diabetic nephropathy in a type II diabetes mellitus rat model. International Journal of Biological Macromolecules 147 (2019).

9. Wang, J. et al. Research progress on Traditional Chinese Medicine syndromes of diabetes mellitus. Biomed Pharmacother 121, 109565 (2020).

10. A refined-JinQi-JiangTang tablet ameliorates prediabetes by reducing insulin resistance and improving beta cell function in mice. J Ethnopharmacol 151, 675-685 (2014).

11. Yang, Z.M., Wang, Y. \& Chen, S.Y. Astragalus polysaccharide alleviates type 2 diabetic rats by reversing the glucose transporters and sweet taste receptors/GLP-1/GLP-1 receptor signaling pathways in the intestinepancreatic axis. Journal of Functional Foods 76.

12. Zhu, H. et al. Antidiabetic and antioxidant effects of catalpol extracted from Rehmannia glutinosa (Di Huang) on rat diabetes induced by streptozotocin and high-fat, high-sugar feed. Chin Med 11, 25 (2016).

13. Yan et al. Catalpol ameliorates hepatic insulin resistance in type 2 diabetes through acting on AMPK/NOX4/PI3K/AKT pathway. Pharmacological Research the Official Journal of the Italian Pharmacological Society (2018).

14. Liu, X. et al. Metformin and Berberine suppress glycogenolysis by inhibiting glycogen phosphorylase and stabilizing the molecular structure of glycogen in db/db mice. Carbohydr Polym 243, 116435 (2020).

15. Cui, L., Liu, M., Chang, X. \& Sun, K. The inhibiting effect of the Coptis chinensis polysaccharide on the type II diabetic mice. Biomed Pharmacother 81, 111-119 (2016).

16. Aierken, A., Buchholz, T., Chen, C., Zhang, X. \& Melzig, M.F. Hypoglycemic effect of hawthorn in type II diabetes mellitus rat model. J Sci Food Agric 97, 4557-4561 (2017).

17. Dehghani, S., Mehri, S. \& Hosseinzadeh, H. The effects of Crataegus pinnatifida (Chinese hawthorn) on metabolic syndrome: A review. Iran J Basic Med Sci 22, 460-468 (2019).

18. Min, A.Y., Yoo, J.M., Sok, D.E. \& Kim, M.R. Mulberry Fruit Prevents Diabetes and Diabetic Dementia by Regulation of Blood Glucose through Upregulation of Antioxidative Activities and CREB/BDNF Pathway in Alloxan-Induced Diabetic Mice. Oxid Med Cell Longev 2020 (2020).

19. Xuegang Sun, L.J. Constructing Integrative Disease and Syndrome Model of Spleen-Deficiency with Transgenic Mice. Liaoning Journal of Traditional Chinese Medicine, 1329-1331 (2016).

20. MA Wen-feng, L.L., HE Shu-heng, YAO Hang-qi, HONG Mei-xian, ZHANG Ji-hong, ZHANG Tie-jun,XU Jun. Rapid identification of classical herbal formulae Baoyinjian's chemical substance based by HPLC-Q/TOFMS). Chinese Traditional and Herbal Drugs 50, 4181-4188 (2019).

21. Hao, Y.M., Huo, J.H., Wang, T., Sun, G.D. \& Wang, W.M. Chemical profiling of Coptis rootlet and screening of its bioactive compounds in inhibiting Staphylococcus aureus by UPLC-Q-TOF/MS. J Pharmaceut Biomed 
180 (2020).

22. Liu, Q. et al. Chemical profiling of San-Huang decoction by UPLC-ESI-Q-TOF-MS. J Pharm Biomed Ana/ 131, 20-32 (2016).

23. Seo, W.D. et al. Identification and characterisation of coumarins from the roots of Angelica dahurica and their inhibitory effects against cholinesterase. Journal of Functional Foods 5, 1421-1431 (2013).

24. Ao, N.N. et al. Chemical basis of hawthorn processed with honey protecting against myocardial ischaemia. Food Funct 11, 3134-3143 (2020).

25. Yang, T.C. et al. Alkaloids from Coptis chinensis root promote glucose uptake in C2C12 myotubes. Fitoterapia 93, 239-244 (2014).

26. Zhang, N. et al. Berberine decreases insulin resistance in a PCOS rats by improving GLUT4: Dual regulation of the PI3K/AKT and MAPK pathways. Regul Toxicol Pharmacol 110, 104544 (2020).

27. Zhang, R., Zhou, J., Jia, Z., Zhang, Y. \& Gu, G. Hypoglycemic effect of Rehmannia glutinosa oligosaccharide in hyperglycemic and alloxan-induced diabetic rats and its mechanism. J Ethnopharmaco/ 90, 39-43 (2004).

28. Knebel, B. et al. Novel Insights into the Adipokinome of Obese and Obese/Diabetic Mouse Models. Int J Mol Sci 18 (2017).

29. Asghar, Z. et al. Insulin resistance causes increased beta-cell mass but defective glucose-stimulated insulin secretion in a murine model of type 2 diabetes. Diabetologia 49, 90-99 (2006).

30. Miao, M., Liu, J., Wang, T., Liang, X. \& Bai, M. The effect of different proportions of astragaloside and curcumin on DM model of mice. Saudi Pharm J 25, 477-481 (2017).

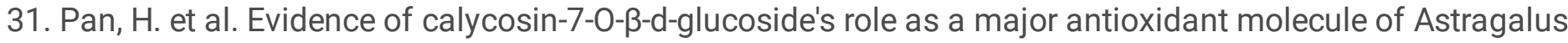
membranaceus Bge. var. mongholicus (Bge.) Hsiao plants under freezing stress. Environmental \& Experimental Botany 109, 1-11 (2015).

32. Liu, J. et al. Global gene expression analysis in liver of $\mathrm{db} / \mathrm{db}$ mice treated with catalpol. Chin J Nat Med 16, 590-598 (2018).

33. Shimada, H. et al. Major constituents of Cistanche tubulosa, echinacoside and acteoside, inhibit sodiumdependent glucose cotransporter 1-mediated glucose uptake by intestinal epithelial cells. Journal of Functional Foods 39, 91-95 (2017).

34. Li, P.C. et al. Therapeutic potential of buckwheat hull flavonoids in $\mathrm{db} / \mathrm{db}$ mice, a model of type 2 diabetes. Journal of Functional Foods 52, 284-290 (2019).

35. Li, J.J. et al. Antidiabetic effects of different polysaccharide fractions from Artemisia sphaerocephala Krasch seeds in db/db mice. Food Hydrocolloid 91, 1-9 (2019).

36. Hu, W. et al. Studies on characteristics and anti-diabetic and -nephritic effects of polysaccharides isolated from Paecilomyces hepiali fermentation mycelium in db/db mice. Carbohydr Polym 232, 115766 (2020).

37. Wu, J. et al. Hypoglycemic effect and mechanism of a pectic polysaccharide with hexenuronic acid from the fruits of Ficus pumila L. in C57BL/KsJ db/db mice. Carbohydr Polym 178, 209-220 (2017).

38. Kim, E. et al. Phyllodulcin, a natural functional sweetener, improves diabetic metabolic changes by regulating hepatic lipogenesis, inflammation, oxidative stress, fibrosis, and gluconeogenesis in $\mathrm{db} / \mathrm{db}$ mice. Journal of Functional Foods 42, 1-11 (2018).

39. Heo, M.G., Byun, J.H., Kim, J. \& Choung, S.Y. Treatment of Dendropanax morbifera leaves extract improves diabetic phenotype and inhibits diabetes induced retinal degeneration in $\mathrm{db} / \mathrm{db}$ mice. Journal of Functional 
Foods 46, 136-146 (2018).

\section{Figures}
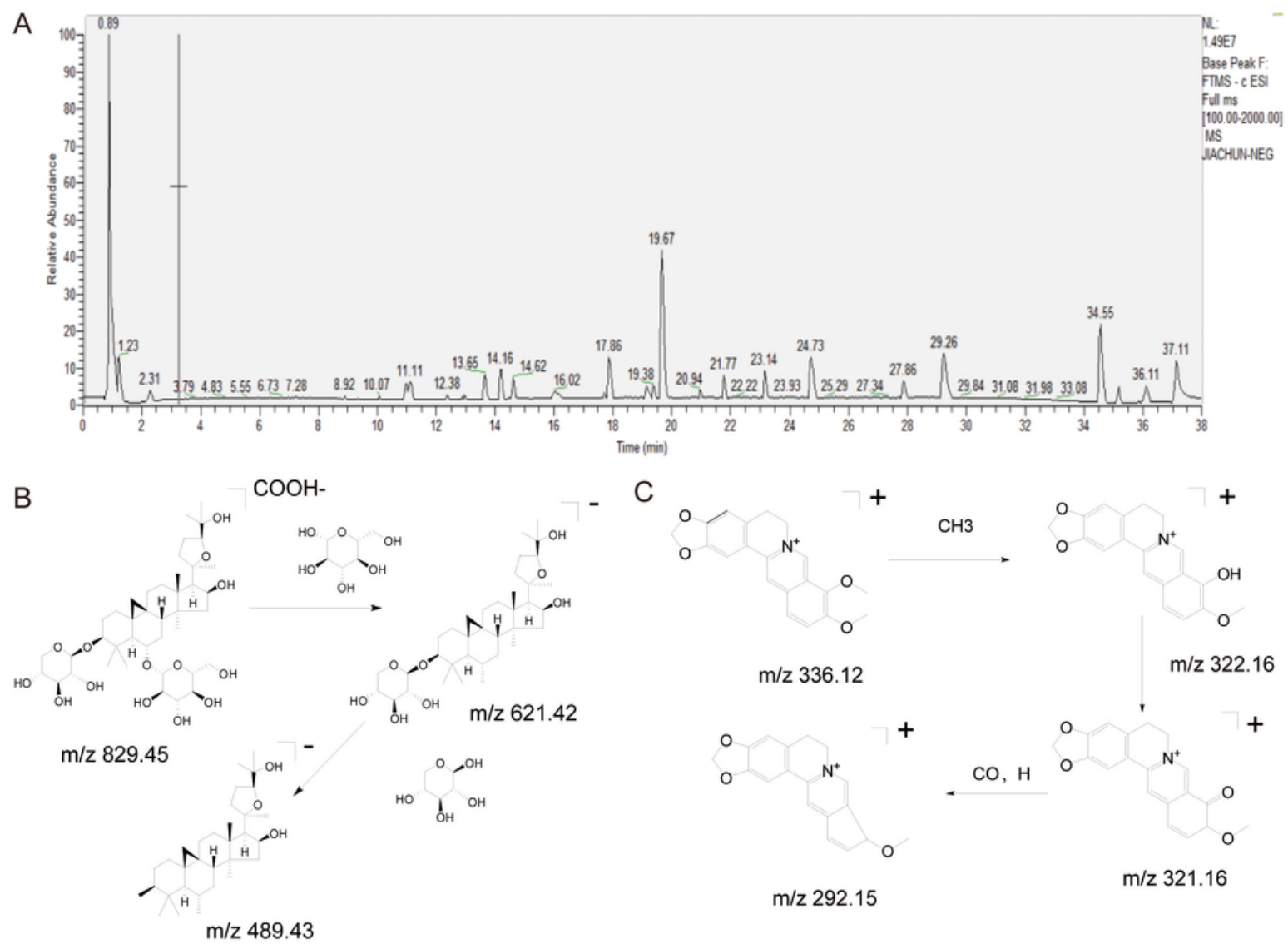

\section{Figure 1}

Chromatogram of the principal ingredients of YQYY as determined by U-HPLC-Orbitrap MS(A), Fragmentation pathways of Astragaloside IV (B) and Berberbine(C) standards. 
A

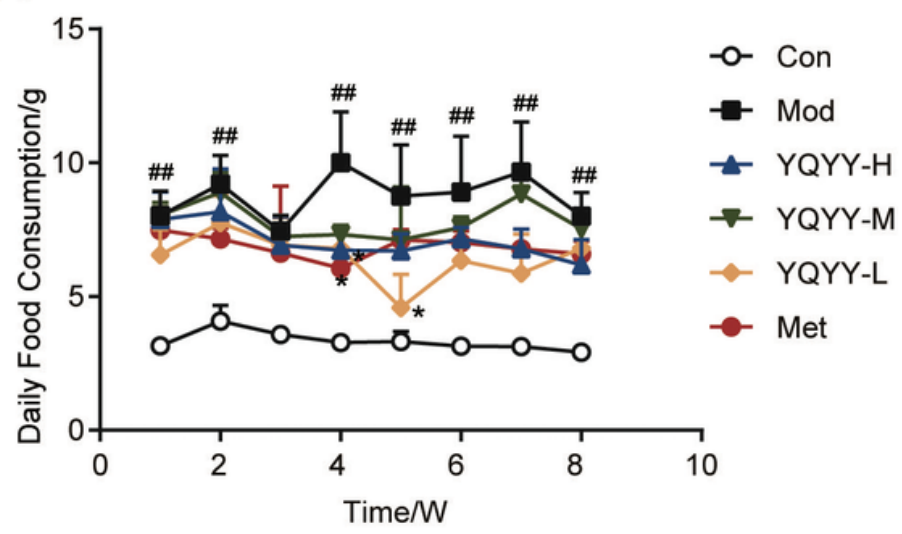

C

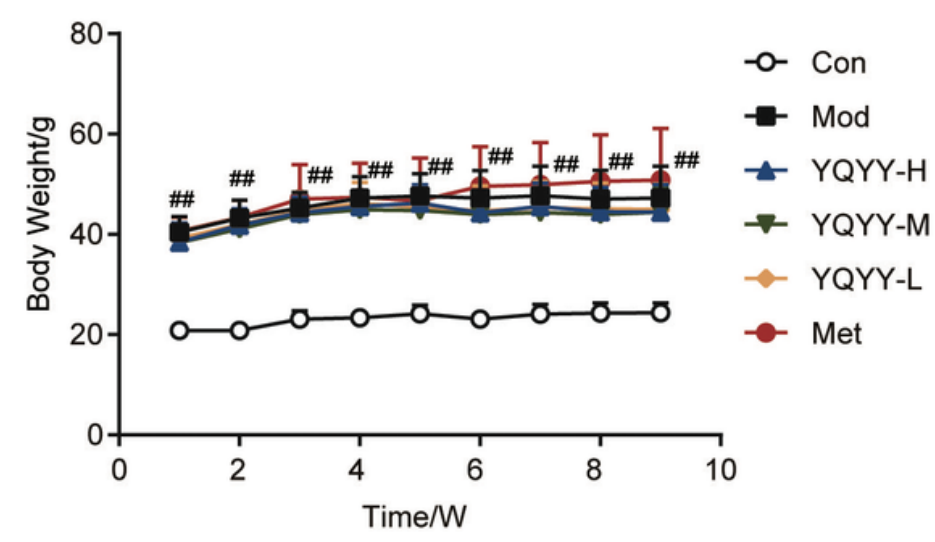

B

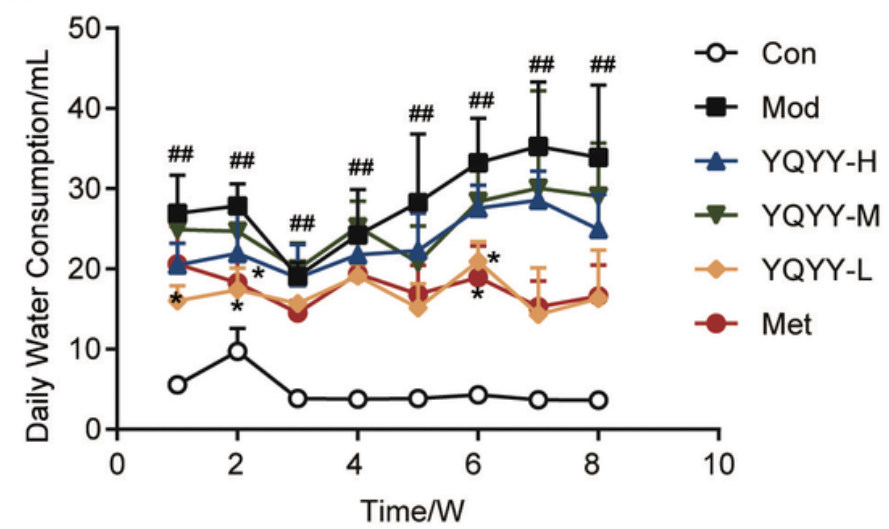

D

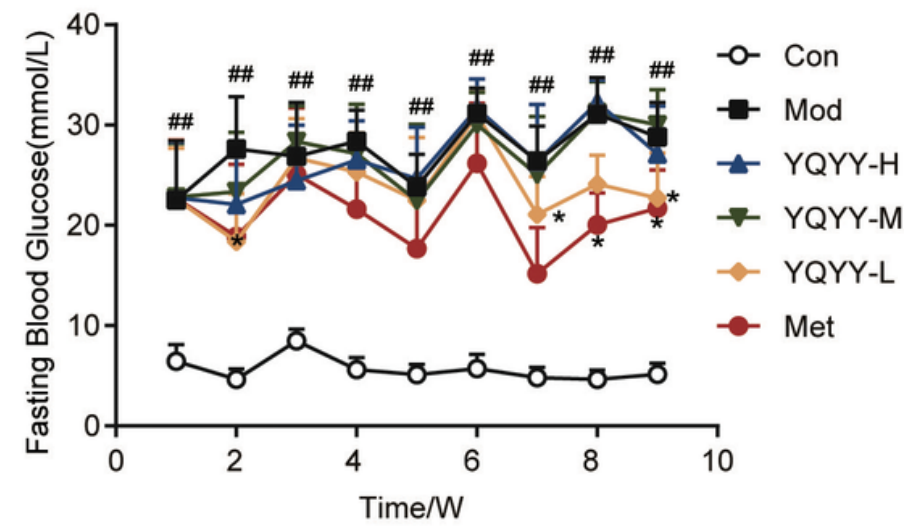

Figure 2

YQYY improved the diabetic phenotype in $\mathrm{db} / \mathrm{db}$ mice. Changes in food consumption (A), water consumption (B), fasting blood glucose (C) and body weight (D). The results are expressed as means $\pm S D(n=10-12)$. Compared with the control group, \# $\mathrm{P}<0.05$, \#\# $\mathrm{P}<0.01$, Compared with the model group, $* \mathrm{P}<0.05$, * $\mathrm{P}<0.01$.

Figure 3

Effects of YQYY on liver histological morphology and glycogen content in $\mathrm{db} / \mathrm{db}$ mice. Tissues stained with H\&E (A), Tissues stained with Oil Red O (B), Average area of the lipid droplet in the hepatocytes (C), Hepatic glycogen content in $\mathrm{db} / \mathrm{db}$ mice (D). Scale bar=50 $\mathrm{mm}$. The results are expressed as means $\pm S D(n=6)$. Compared with the control group, \# $P<0.05$, \#\# $P<0.01$, Compared with the model group, * $P<0.05$, ** $P<0.01$. 

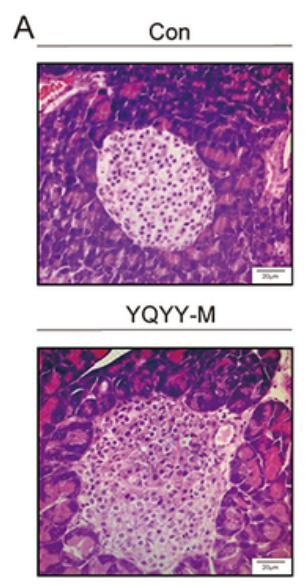

C
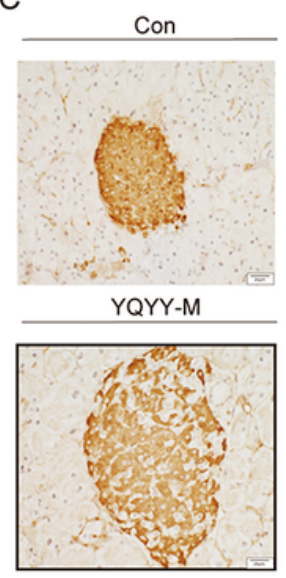

E
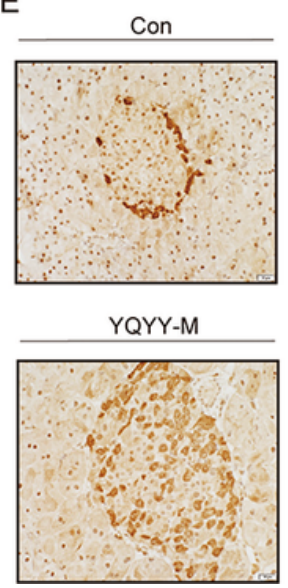

Mod

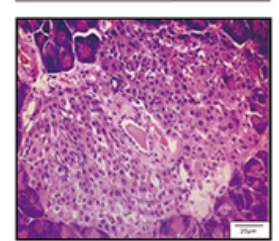

YQYY-L

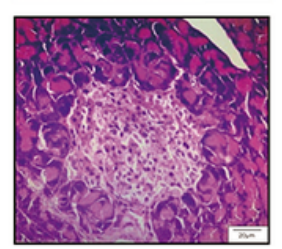

Mod
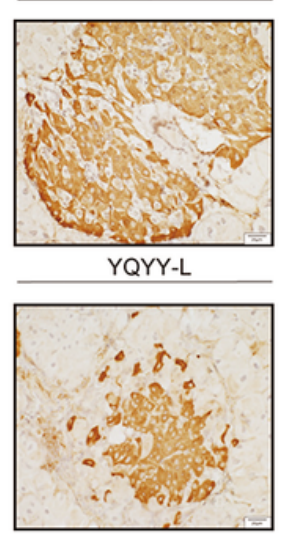

Mod

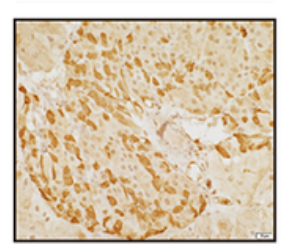

YQYY-L

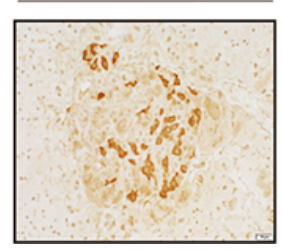

YQYY-H

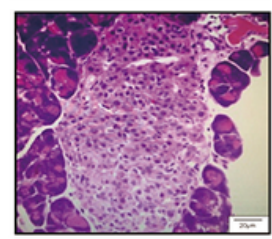

Met

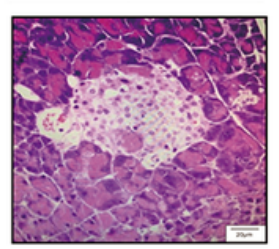

YQYY-H

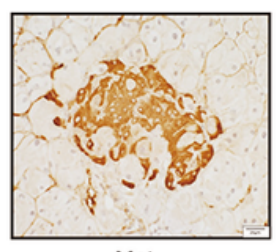

Met

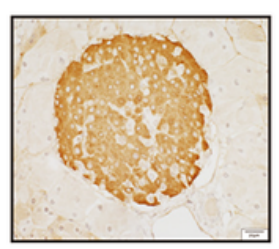

YQYY-H

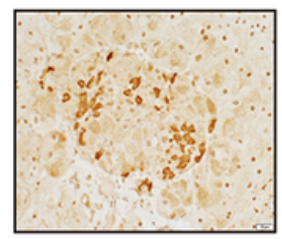

Met

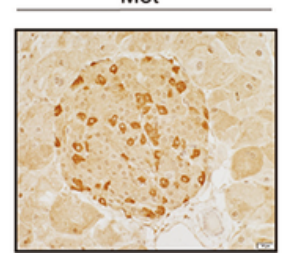

B

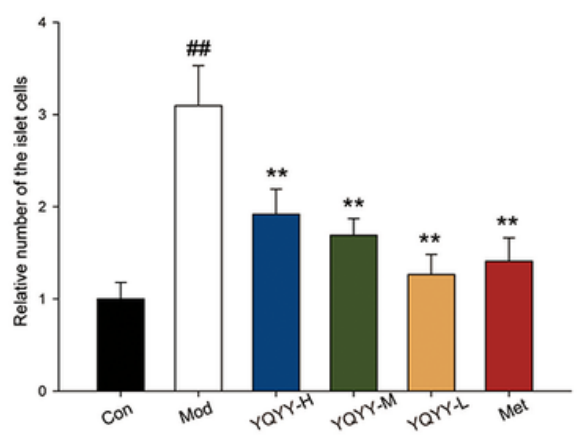

D

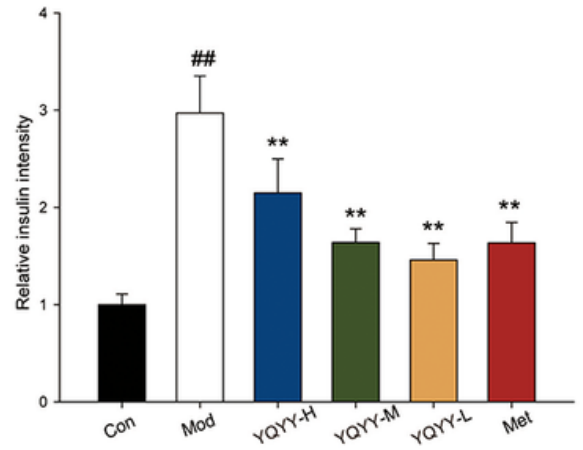

F

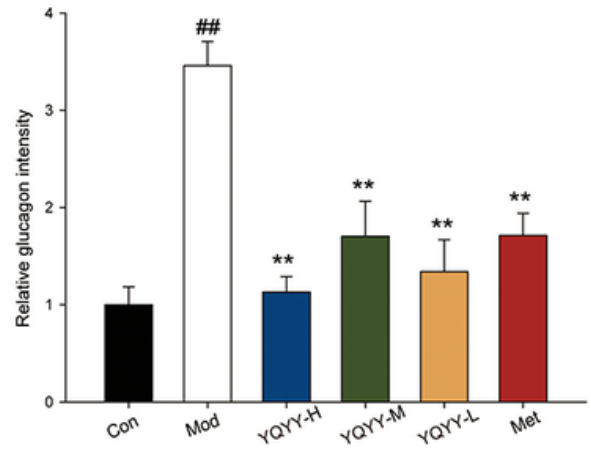

Figure 4

Effects of YQYY on pancreas in db/db mice. Morphological changes of pancreatic tissue (A), The number of parenchymal cell wasquantified using Image-Pro Plus software (B), Immunohistochemically-stained pancreatic tissueusing markers for insulin(C) and glucagon (E). Relative insulin (D) and glucagon (F) intensity in pancreatic islets quantified using Image-Pro Plus software.Scale Bar $=20 \mu \mathrm{m}$, The results are expressed as means \pm SD (n =6). Compared with the control group, \# P<0.05, \#\# P<0.01, Compared with the model group, * $P<0.05, * \star P<$ 0.01 . 

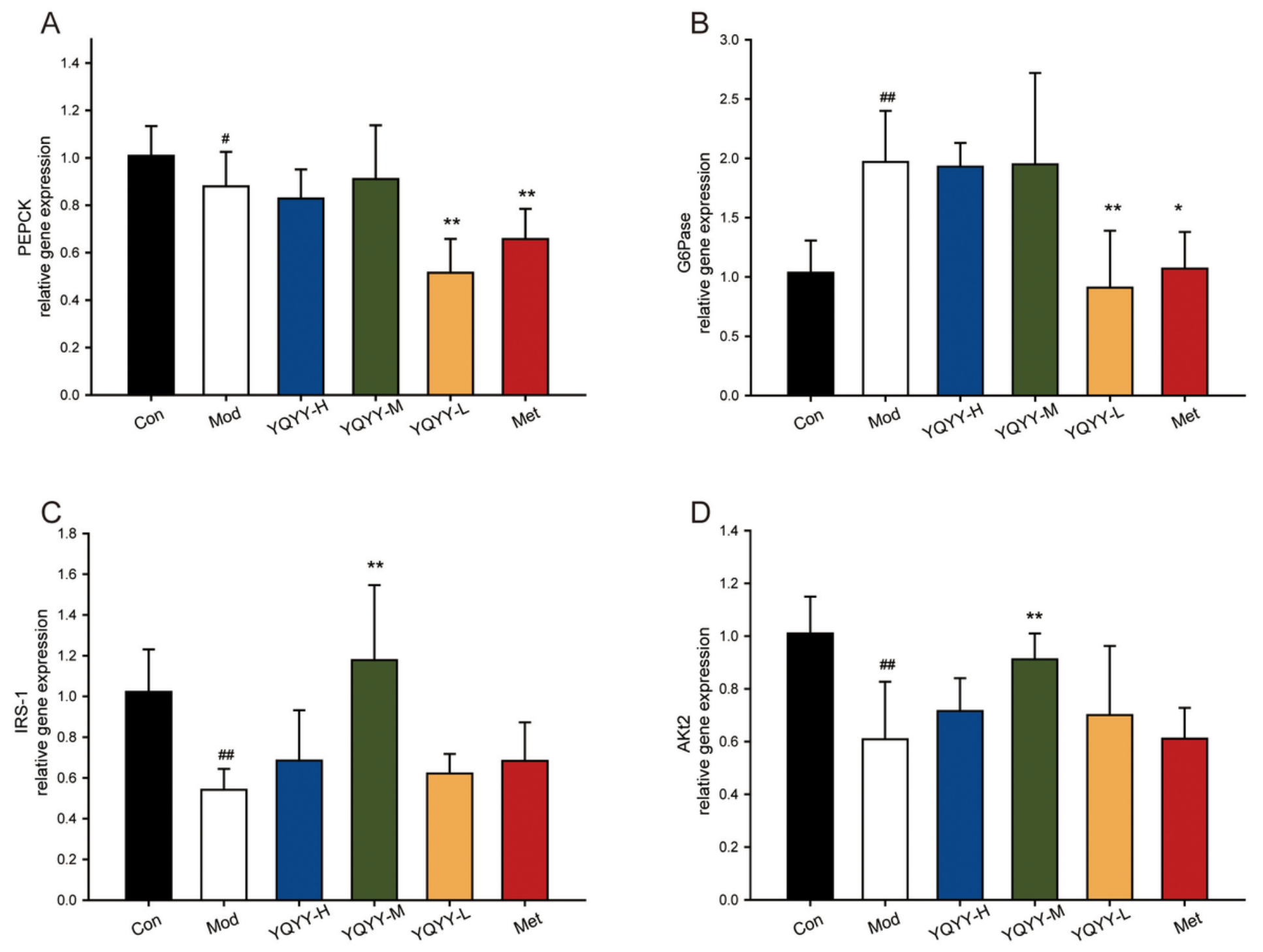

Figure 5

Effects of YQYY on expression levels of mRNA related to glucose metabolism in $\mathrm{db} / \mathrm{db}$ mice. mRNA expression of PEPCK (A), G6Pase (B), IRS-1 (C), and Akt2 (D). The results are expressed as means \pm SD $(n=4)$. Compared with the control group, \# $P<0.05$, \#\# $P<0.01$, Compared with the model group, ** $P<0.05$, ** $P<0.01$. 
A
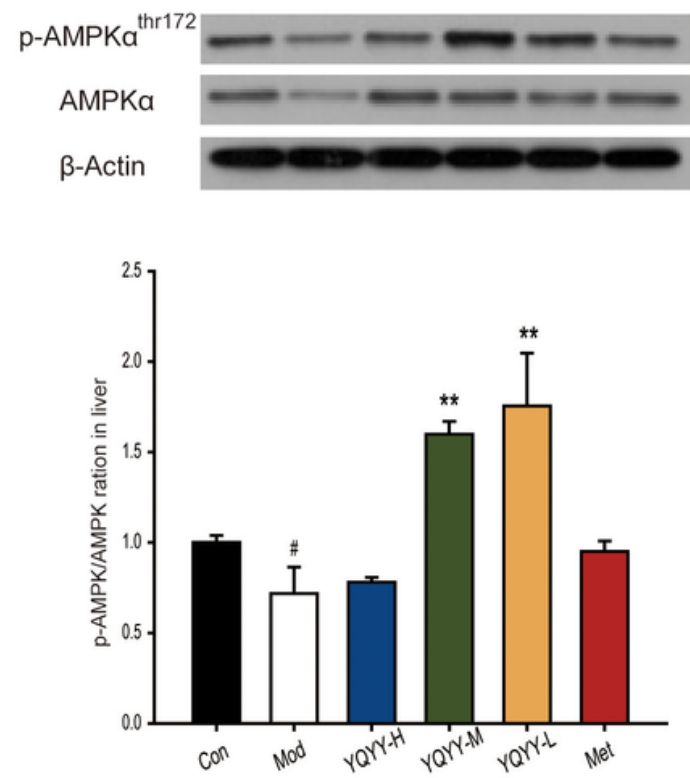

B

p-GSK-3 $\beta$

$\beta$-Actin

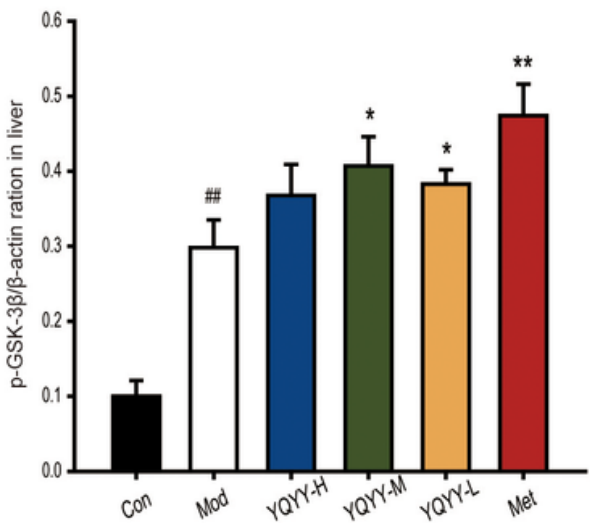

C

GS

B-Actin

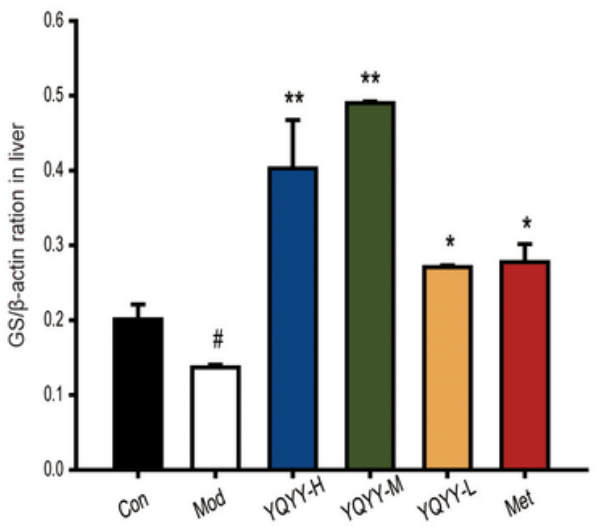

Figure 6

Effects of YQYY on protein expression levels of AMPK and p-AMPK (A), p-GSK-3ß (B), and GS (C) in liver tissue. The results are expressed as means $\pm S D(n=4)$. Compared with the control group, \# $P<0.05$, \#\# $P<0.01$, Compared with the model group, * $* \mathrm{P}<0.05$, ** $\mathrm{P}<0.01$. 